\title{
SUBSTITUTOS DO “NOVO” MUNDO PARA AS ANTIGAS PLANTAS RARAS: UM ESTUDO DE CASO DOS BÁLSAMOS
}

\author{
Ana Maria Alfonso-Goldfarb, Márcia H. M. Ferraz* e Maria Helena Roxo Beltran \\ Centro Simão Mathias de Estudos em História da Ciênciä, Faculdade de Ciências Exatas e Tecnologia, Pontifícia Universidade \\ Católica de São Paulo, Rua Caio Prado, 102, 01303-000 São Paulo - SP, Brasil
}

Recebido em 12/11/09; aceito em 26/2/10; publicado na web em 21/5/10

\begin{abstract}
"NEW" WORLD SUBSTITUTES FOR ANCIENT RARE PLANTS: A STUDY CASE ON BALSAMS. Convinced that the "true balsam" was lost forever, Conrad Gesner described other substances with similar healing virtues. However, he was not the only one in the $16^{\text {th }}$ to search for other varieties of balsamic oleoresins. The arrival of the Europeans to the Americas allowed the finding of native plants with properties similar to those of the original balsam, including Balsam of Peru, Balsam of Tolu and particularly in the Brazilian area, Balsam of Copaiba. Focusing on the Brazilian context, this paper analyzes two different moments in the transit of the newly found varieties of balsams to the pharmacopeia and materia medica.
\end{abstract}

Keywords: History of Chemistry; balsams; Brazil.

\section{INTRODUÇÃO: A ORIGEM DE UM MITO}

Como muitas outras Simpliceae, os bálsamos tiveram grandes problemas de identificação e classificação desde tempos antigos. Nesse caso particular um dos focos de tais problemas parece ter sido a criação de um "mito de origem". Na enorme e variada literatura sobre essa classe de substâncias persistiria, até o século XVIII, o mito de um bálsamo "original", o único verdadeiro e insuperável, chamado pelos antigos de Bálsamo do Egito ou da Judeia. ${ }^{1}$

Para um farmacólogo moderno, pode parecer incrível que essa substância, semelhante em composição e propriedades a outros bálsamos, tenha causado tanta comoção por milênios. No entanto, há razões que explicam o nascimento desse mito que, uma vez estabelecido, chegou até a modernidade virtualmente por inércia.

Antes de tudo, é preciso lembrar que essa substância já era rara na Antiguidade, assim como rara e difícil de cultivar sempre foi a planta de que provinha. Acrescente-se a isso o fato de sua fragrância e poder de cura inigualáveis serem conhecidos desde tempos antiquíssimos, encontrando-se mencionados no texto bíblico (Gênese 37:25; Jeremias 52:16). Finalmente, recordemos que, provavelmente, esse óleo fragrante teria sido o primeiro a receber o nome de "bálsamo", uma possível epêntese do termo hebraico equivalente a "principal" ou "senhor" dos óleos, apenas mais tarde atribuído a substâncias similares.

Assim, é fácil entender que esses elementos gerassem lendas, contadas e ampliadas por autores respeitados, como Plínio, Flávio Josefo e Galeno, chegando como fontes fidedignas até o início dos tempos modernos. ${ }^{2}$ Do outro lado, a escassez efetiva desse bálsamo foi motivo de muita cobiça, fraudes e uma busca intensa por substitutos. Desde Dioscórides (século I EC) até pelo menos Andrés Laguna (século XVI), dezenas de autores alertaram sobre as constantes falsificações desse bálsamo, mas também ofereciam possíveis substitutos - certamente, sempre considerados inferiores. ${ }^{3}$

Por outro lado, os autores árabes medievais se distinguiram por sua minuciosa diferenciação entre esse bálsamo e os demais, seguramente por conhecerem de perto a planta de que era extraído. A pequena árvore que hoje chamamos de Commiphora gileadense (L.) C. Chr. (ou C. opobalsamum) parece ser oriunda do Oriente Médio.

*e-mail: mhferraz@pucsp.br

\#Programa de Estudos Pós-Graduados em História da Ciência
Cultivada em jardins especiais, sempre com muita dificuldade, a extração e comércio de seu bálsamo foram controlados durante o Império Árabe. ${ }^{4}$ Todavia, a partir da dominação turca, seu bálsamo passaria a ser considerado um bem do estado e sua exportação, proibida. Assim, esse tesouro vegetal, presente de príncipe e partícipe da consagração dos "santos óleos" passaria de escasso a praticamente inexistente em outras partes do mundo. ${ }^{5}$

Dentre as muitas lendas que chegaram à Europa a respeito de seu desaparecimento, uma versão será contada por Conrad Gesner em seu famoso Tesouro de Euonymus. ${ }^{6}$ Segundo essa, o jardim dos bálsamos havia sido destruído e os jardineiros que poderiam tê-lo replantado ou guardado seus segredos teriam sido mortos por soldados turcos em 1516. Baseado em várias fontes contemporâneas, Gesner afirma que o "verdadeiro bálsamo" estava perdido para sempre.

Como no caso de muitos outros autores, não é possível saber se Gesner efetivamente conheceu esse bálsamo ou se apenas estava citando outras fontes ao se referir a ele como:

"O suco dourado obtido desta preciosa especiaria que cura ferimentos e elimina rugas, e conserva os rostos de homens mortos contra a corrupção; quebra também as pedras dos rins. Apaga as manchas dos olhos, resiste o veneno, especialmente acônito, cicuta, e o tremor das próprias febres, e em todas estas coisas, as virtudes do Bálsamo são excelentes."

Por certo, sabemos apenas que Gesner - assim como outros prestigiosos autores da época - se dedicou a uma busca insistente por substitutos entre "óleos de gomas, ou licores, espessados ou congelados, e resinas, óleos de córtex, e óleos obtidos de madeiras". Uma vez que, a partir desses, elaborou, efetivamente, os preparados balsâmicos presentes no capítulo "Do verdadeiro Bálsamo, e anti bálsamo, isto é, Óleos compostos pela arte, que são utilizados ao invés do verdadeiro Bálsamo dentro e fora do corpo". ${ }^{8}$

\section{Fontes para o estudo dos novos bálsamos}

Outros estudiosos, menos famosos que Gesner, mas muito antes dele, já haviam começado essa busca persistente. Não por acaso, em 1516, a mesma data mencionada na lenda contada por Gesner (embora incorretamente datado em 1534 por vários estudiosos, correspondendo à 
data da tradução alemã), Pietro Martyr d'Angleria, cronista do Conselho das Índias encarregado por Carlos V de descrever as descobertas dos espanhóis no "Novo Mundo", 9 fez publicar em Alcalá o conjunto de suas primeiras 3 Décadas, em que já é mencionado o Bálsamo de Copaíba (Copaifera L.). Na terceira Década, elaborada a partir do relato do piloto de um dos navios enviados a Hispaniola, Cuba e outras ilhas e dedicada ao papa Leo X, Martyr fala de piches encontrados em algumas partes:

"[... ]Na mesma terra, eles colhem o piche que transpira das rochas, muito mais dura e azeda que o piche da árvore [...] Essa terra também produz piche em dois tipos de árvores, como no Pinheiro, e outra chamada de Copeia. Não preciso falar do Pinheiro [...] Falemos, portanto, alguma coisa sobre a outra, chamada de Copeia, também se colhe piche dela, como do pinheiro, embora alguns falam que é colhida destilando ou gotejando a madeira quando queima. É algo estranho ouvir isto último, e como uma provisão necessária da natureza é mostrada nela." 10

Vale dizer que, a então poderosa coroa da Espanha, sempre com olhos por toda parte, tinha pressa para encontrar alternativas ao comércio recém-fechado pelo Império Turco. Mas, apesar dessas notícias primevas sobre a copaíba, seriam os bálsamos de espécies variantes do Myroxylon peruiferum L. (M. balsamum Harms) as novas estrelas desse comércio no século XVI. E novamente será Angleria a publicar, na Década VII, de 1525 (mais uma vez, mal datada pelos estudiosos), uma notícia alvissareira sobre um possível sucedâneo para o bálsamo encontrado na Hispaniola. Segundo ele:

"Um certo estudioso Italiano chamado Codrus, viajando por esses lugares para investigar as naturezas de coisas, tendo partido, ficou autorizado (porque nenhum estrangeiro pode fazer legalmente de nenhuma outra forma), convenceu os espanhóis que este [um licor] tinha a força do Balsamum”. ${ }^{11}$

Essa planta foi descrita anos mais tarde em detalhe por Fernández de Oviedo, que a chamou de "novo bálsamo" ou ainda "planta a que os cristãos chamam de bálsamo artificial". ${ }^{12}$ Apesar das controvérsias mantidas até hoje, tudo parece indicar que essa planta era uma das espécies de Myroxylon encontrada por europeus nas Américas. A esse gênero também pertenceriam as plantas das quais eram extraídos os conhecidos bálsamos do Peru e de Tolu que, em conjunto, transformaram de maneira radical o comércio do produto naquela época. Foram tais as quantidades desses bálsamos exportadas para a Europa no meio do século XVI que Laguna comenta:

"Faz dois anos, um mercador milanês trouxe a Roma um certo balsamo da Nova Espanha que tinha a cor e o corpo de perfeitíssima qualidade [...] E dado que segundo a prova se viu não tratar-se do bálsamo verdadeiro, senão de um óleo puríssimo de Estoraque, ainda assim, foi vendido naqueles tempos por sete ou oito ducados a onça, até que depois vindo de Sevilha uma quantidade copiosa deste começou a cair de reputação e preço ainda que na verdade seja [...] um soberano remédio." 13

Essa tendência seria permanente, pois quase 29 anos depois, em seu Herbolaria de Índias, Nicolás Monardes parafraseia Laguna e acrescenta:

"Isto acontece pela abundância das coisas ou a sua escassez, pois quando custava muito caro, todos se aproveitavam de suas virtudes e depois como veio a custar tão vil preço, não o têm em conta, sendo ele o mesmo bálsamo que era então, quando custava cem ducados por onça, que o de agora que não tem preço." ${ }^{14}$

Arguto em suas observações e bom conhecedor dos materiais que lhe chegavam das Américas, Monardes comenta na sequência que, se não fosse por outra coisa, já teria valido a pena a descoberta das "Índias", somente pelo fato de ali se encontrar o bálsamo da Nova Espanha que, segundo seu parecer "não era menos que aquele do Egito" e, de toda forma, este último já havia desaparecido.

Parafraseando Monardes, seria possível dizer que se para outra coisa não tivessem servido os bálsamos das Américas, pelo menos valeram para iniciar o desmonte do "mito de origem" a respeito de um bálsamo verdadeiro e insuperável.

A proximidade desse tipo de substâncias, no caso de Monardes, e das próprias plantas, no caso de alguém como Francisco Hernandez, ${ }^{15}$ foi tão revolucionária para a visão que se tinha dos bálsamos, quanto seu enorme influxo em território europeu. No entanto, o óleo de copaíba, que parece ter sido o primeiro dos bálsamos identificado nas Américas, participaria apenas em parte desse processo revolucionário. A partir do que se soube (ou se deixou de saber) sobre essa substância, é possível, todavia, oferecer alguns dos contornos da complexa e difícil história da farmácia em Terra brasilis.

\section{Um "virtuoso" bálsamo brasileiro na botica inaciana}

As notícias sobre o bálsamo da copaíba dadas por Angleria foram similares às reportadas por diversos viajantes que, ao longo do século XVI, estiveram na América do Sul. ${ }^{16}$ Curiosamente, porém, não teria havido, nesse período, qualquer iniciativa para sua exploração e comércio em grande escala. Algo deveras peculiar, num momento em que outros bálsamos americanos faziam história. Mas, como veremos mais tarde, houve motivos de sobra para que essa estranha situação acontecesse. Para o que nos interessa agora, é suficiente lembrar que a maior concentração das plantas desse bálsamo estava em território brasileiro... e esse território permaneceu quase desconhecido nos primeiros séculos da colonização, até mesmo pela metrópole portuguesa.

A expressão "quase desconhecido" serve aqui para resguardar casos como o dos chamados "bandeirantes" ou, ainda, o da pirataria e de maneira particular, o dos jesuítas. Esses últimos conheceram como ninguém as riquezas ainda incógnitas da América portuguesa. No caso das plantas havia, além de tudo, um interesse mais que especial. De fato, os jesuítas, em suas atividades de evangelização, mantinham em seus colégios uma botica para a preparação e fornecimento de medicamentos a partir de drogas nativas. E para isso, buscaram conhecer a rica natureza brasileira e sua utilização pelos indígenas. ${ }^{17}$

Numa carta, escrita em 1560, José de Anchieta afirma atender a um pedido do Prior da Companhia de Jesus para que "se escrevessem as coisas que, entre nós, fossem ou dignas de admiração, ou desconhecidas deste mundo". Referindo-se ao que havia encontrado na província de São Paulo, Anchieta descreve algumas plantas de uso medicinal. Especialmente sobre a copaíba, diz:

\footnotetext{
"De entre as árvores, uma parece digna de menção (posto que haja outras que destillam um liquido, similhante a resina, e que serve para remédio) a qual distilla um succo delicadíssimo, que alguns querem que seja bálsamo; o qual, a principio pelos furinhos, feitos pelo caruncho, ou também pelas incisões abertas com facas, ou machadinhos, corre como azeite, depois, coagulando-se, parece apresentar a apparencia de bálsamo: o cheiro que desprende não é muito forte, mas agradabilíssimo; e é excellente para curar feridas, porque nem mesmo restam vestígios de cicatrizes, como dizem que se provou pela experiência."18
} 
Essa carta ficou inédita até 1898, no entanto, conhecendo-se a prática da Companhia de Jesus de fazer circular as informações obtidas nas diferentes regiões por onde andavam, podemos dizer que descrições como essas ajudaram a tornar bem mais conhecidas substâncias como o bálsamo de copaíba. ${ }^{19}$

De todo modo, é um documento jesuítico que oferece uma ampla descrição dos "maravilhosos" efeitos desse bálsamo. Estudado no século XIX pelo renomado bibliógrafo argentino Pedro Arata e ainda pouco conhecido, vale a pena dedicar-lhe alguma atenção. Arata estudou 4 versões desse documento, concluindo que esse, assim como outros herbários, teria como original uma obra manuscrita do Jesuíta Pedro Montenegro, possivelmente produzida em finais do século XVII, mas que começou a ser mencionada a partir do início do século XVIII. ${ }^{20}$

A partir de nosso cotejo da obra estudada por Arata, pudemos verificar que uma versão anônima desta encontra-se depositada na Biblioteca Nacional do Rio de Janeiro, localizada por primeira vez por uma destas autoras, em 2002. Trata-se de um manuscrito em castelhano do período, com 230 fls. incluídos índices de plantas e de enfermidades, além de um glossário de termos, cujo título anuncia: "Curiosidad un libro de medicina escripto por los jesuítas en las Misiones del Paraguay en el año de 1580". ${ }^{21}$

Mesmo que nenhuma pista levasse ao nome de Pedro Montenegro como autor, a datação é um tanto suspeita, já que as missões jesuíticas no Paraguai só tiveram início oficial em princípios do século seguinte. ${ }^{22} \mathrm{O}$ autor, que teria trabalhado como médico no Hospital General de Madrid, alonga-se nas explanações sobre a medicina tradicional do período. Mas seu trabalho duro, que ocupa a maior parte da obra, trata dos sucedâneos locais de medicamentos, bem como daqueles de que só as Américas são possuidoras. Por isso recomenda:

\begin{abstract}
"Quem tiver gênio ou inclinação natural inclinada à investigação sua tenha a luz por onde possa com segurança se governar e adiantar a descoberta de muitas mais melhores das que eu investiguei por ser esta America mais fértil e abundante nelas que nenhuma das outras três partes do Mundo, $e$ estou em que ela sozinha possui tantos bens de plantas que julgo igual às das outras três partes juntas por sua grande louçanidade e abundância da Calor e Umidade." ${ }^{3}$
\end{abstract}

Seu rol de Simpliceae, porém, não alcança mais que 70 entradas, pois nota-se que pretende relacionar as mais importantes e necessárias; mas, entre elas, naturalmente, estão os bálsamos. Um deles é o bálsamo negro do Paraparay, uma árvore cuja descrição lembra as espécies do Myrocarpus frondosus Fr. Allem. referidas nas farmacopeias germânicas desde o século XVII. O autor, que parece ter sido um bom herborizador, detém-se na descrição dos aromas e sabores de suas cascas, folhas e favas e recomenda seu óleo, denso e escuro, contra supurações e chagas venéreas. ${ }^{24}$

O outro bálsamo negro seria o da Caaroba, provavelmente pela descrição, uma das espécies brasileiras de Myroxylon (conhecida popularmente como cabreúva) e que o próprio autor identifica como sendo muito frequente no Brasil, de onde lhe viria o nome. Descreve outra vez, com prazer, os odores e sabores das partes dessa planta e considera que seu bálsamo teria as mesmas "virtudes" miraculosas do guaiaco contra males venéreos. ${ }^{25}$

Mas, sem dúvida, seu bálsamo preferido é o de copaíba, cuja entrada está entre as primeiras e mais importantes substâncias medicamentosas desse códice. Talvez, não por acaso, nada diz de sua planta, indicando que dela só conhecia bem o bálsamo. Em compensação, ele nos oferece uma notícia das mais interessantes. Pois, segundo lhe haviam informado, o bálsamo da copaíba tornara-se famoso e muito procurado em várias partes do mundo, inclusive na China e no Japão, alcançando altíssimos preços. Ainda segundo a mesma fonte de informação, isso se dava devido a suas virtudes portentosas de aquecer e curar a alma, assim como as feridas "mais penetrantes e perigosas em até 14 horas". Ou seja, é possível dizer que enquanto outros bálsamos americanos eram vendidos por centavos, o óleo de copaíba, escasso no comércio, transformou-se num verdadeiro elixir, precioso e caro. Todavia, o autor jesuíta não se prende por muito tempo nas divagações de seu informante e logo nos apresenta suas próprias observações sobre esse bálsamo, quando diz:

"Como o tenho por experimentado em casos mui desesperados de ferimentos mui penetrantes assim da Cabeça, como do Ventre e o Peito e em musculos, e nervos Cortados, é só Aquecé-lo numa colher, de metal até que ferva e solte fumaça [...] assim Quente aplicá-lo nos ferimentos tão Quente quanto o paciente puder sofrer." 26

E passa a descrever em detalhe o caso de uma doente a quem conseguiu salvar com o bálsamo depois de ela ter recebido "os Sacramentos". Mas, naturalmente como qualquer texto da época, esse também oferece indicações múltiplas, estranhas e muitas vezes internas, para o uso do óleo de copaíba. ${ }^{27}$ Em todo caso, como bom jesuíta, suas indicações sempre se dão de forma objetiva e clara, para serem usadas em qualquer dispensário inaciano. E nunca, em momento algum do texto, fala-se de qualquer bálsamo como sucedâneo de um bálsamo original ou, muito menos, superior. E, note-se mais uma vez, que seu autor era versado na literatura médica clássica. Portanto, a essa altura, pelo menos para os inacianos instruídos na arte médica e na botica, já haviam desaparecido as amarras míticas do bálsamo original e inigualável.

\section{Conhecendo nossos bálsamos através de estrangeiros}

Ainda que um grande número de trabalhos tenha sido realizado sobre o gênero Copaifera L., persistem até hoje dúvidas e equívocos sobre a composição química e atividade farmacológica dos óleos, assim como sobre a identificação botânica das diferentes espécies de copaíba. Sabe-se que essas árvores são nativas de parte da América Latina e da África Ocidental. Trabalhos recentes apontam a existência de 72 espécies do gênero Copaifera, sendo que 16 dessas espécies aparecem apenas no Brasil que, assim, é o país onde se pode encontrar o maior número de espécies. ${ }^{28}$ Essa abundância teria tornado a copaíba, desde os primeiros tempos das descobertas, o "bálsamo brasileiro".

Portugal e Espanha haviam dividido entre si as terras americanas recentemente "descobertas", no entanto, seguiram caminhos muito diferentes no que respeita às medidas aplicadas às suas colônias na América. Enquanto a Espanha se preocupava em conhecer as "novas" terras, Portugal interessava-se minimamente pelo Brasil, dedicando-se pouco a protegê-lo das invasões que se sucederam no século XVI. Apenas com a descoberta do ouro no século seguinte, passou a adotar uma política de restrição à entrada de estrangeiros e também de circulação dos reinóis. ${ }^{29}$

Ainda diferente da Espanha, Portugal não se preocupou, nos primeiros séculos depois da chegada à América, em patrocinar viagens de reconhecimento de suas riquezas e explorava simplesmente o que já se havia tornado bem conhecido. Mais que isso, as informações que porventura fossem obtidas sobre o Brasil, deviam ficar secretas, acessíveis apenas aos membros do governo. O interesse pelas descrições do "Novo Mundo" era, entretanto, muito grande, como provam as publicações de inúmeras coletâneas sobre as descobertas e também a ação de piratas na captura dos preciosos produtos das Américas, mas também dos textos que as descreviam. ${ }^{30}$ 
Para manter afastados os estrangeiros e evitar as tentativas de exploração indevida das riquezas de suas colônias, o governo português mantinha, também, uma estrita censura sobre a imprensa. Um bom exemplo dessa política é a história da publicação do texto Cultura e Opulência do Brasil, saído dos prelos em 1711, sob o nome de André João Antonil.

O próprio autor, um jesuíta, o publicou com um codinome, pois, certamente, tinha conhecimento das restrições impostas pela Coroa Portuguesa. Essa, quando se deu conta da publicação, mandou recolher e queimar todos os exemplares. Felizmente, alguns se salvaram e podemos hoje saber que o texto tratava dos mais importantes interesses dos portugueses no Brasil: produção do açúcar de cana, mineração do ouro e criação de gado para a produção de carne e couros. ${ }^{31}$ Mesmo quando os membros do governo português necessitavam de informações sobre a sua mais rica colônia, tinham que lançar mão de textos publicados em outras partes.

Assim, a maior parte dos textos compostos sobre o Brasil entre os séculos XVI e XVIII - e também a história de sua elaboração - seria conhecida apenas séculos após, quando se publicaram traduções e originais de inúmeras descrições da colônia. Hoje, graças ao esforço concentrado de estudiosos e de editoras, principalmente a partir do século XX, está acessível em português uma imensa massa de crônicas, relatos de viagens e memórias de naturalistas elaboradas em diferentes línguas, incluindo a nossa.

Como um dos resultados da política portuguesa, o Brasil foi durante vários séculos um desconhecido para os próprios portugueses e brasileiros. Mudanças ocorreram, entretanto, na segunda metade do século XVIII, devido principalmente às ações arquitetadas pelo primeiro-ministro português, o Marquês de Pombal, atingindo também o sistema de ensino português. Assim, foram contatados estudiosos de origem portuguesa vivendo fora do país que pudessem auxiliar nos planos das modificações almejadas. É o caso de Antonio Ribeiro Sanches, influência importante para a reforma de Universidade de Coimbra, promulgada em 1772. Nesse contexto, pela primeira vez em Portugal, um curso superior contemplava o ensino de História Natural, Física Experimental e Química, como parte do "Curso Filosófico", destinado a formar "filósofos naturais". Estes, a cargo do governo, deveriam fazer o reconhecimento das riquezas do reino, em especial de suas colônias, de que se tinham poucas informações. ${ }^{32}$

Não por coincidência, encontramos, no mesmo ano da reforma da Universidade, o já mencionado Ribeiro Sanches, cumprimentando o fundador da Academia de Medicina e História Natural do Rio de Janeiro ao mesmo tempo em que lamenta ser necessário recorrer ao que haviam escrito os holandeses (ou seja, Willem Piso e Georg Margraff) para se ter alguma informação sobre o Brasil. Enquanto os espanhóis haviam tido, segundo Sanches:

"a habilidade de fazer entrar no Comércio a Coxonilha, a Quina, a Jalapa, a contra-erva, os balçamos, a cevadilha [...] nós [os portugueses] tão desasados [desajeitados] desde duzentos anos não tivemos habilidade de fazer entrar no comercio a raiz de milhomens, a casca barbatimão, a Almecega; e outras mil raizes, frutos, e cascas, que podem servir na Medicina e nas artes tintas." ${ }^{33}$

Apenas poucas coisas, segundo Sanches, haviam-se "descoberto" sobre o Brasil e suas produções pois, além dos materiais para a tinturaria, eram conhecidos alguns vegetais com qualidades medicinais. E, ainda mais interessante para esta pesquisa, Sanches afirma: "E admiro-me como o óleo de copaíba e Ipecacuanha chegaram a ser conhecidos, o que devemos aos quondam [antigos] jesuítas". ${ }^{34}$ Se considerarmos que, à época em que esta memória era escrita, os jesuítas estavam proibidos de exercer suas atividades no reino português, muito mais significativo se torna o reconhecimento de que a divulgação do uso de tão importantes medicamentos se devia aos padres da Companhia.

Os relatos dos jesuítas - discutidos anteriormente - não são, entretanto, os únicos sobre os bálsamos ou, em especial, sobre a copaíba e a eles se somam muitos outros. Relativamente aos exemplares das árvores encontrados no Brasil, hoje sabemos que portugueses e "brasileiros" (com formação e interesses diferentes), mas também estrangeiros citaram a droga e seus efeitos surpreendentes, ressaltando, algumas vezes, o uso medicinal que dela faziam os indígenas.

Assim, em 1587, Gabriel Soares de Sousa, que se dedicava na Bahia às atividades agrícolas e de extração, escreveu uma relação do que havia encontrado na capitania. Na parte dedicada às "árvores e ervas de virtude que há na Bahia", encontramos uma longa descrição das árvores que dão bálsamos. Para um colono como Soares de Sousa, certamente não familiar com as fontes antigas, "a árvore do bálsamo" era a "cabureiba", ou seja, Myroxylon peruiferum L., produtora do que passou a ser conhecido também como Bálsamo do Peru ou Bálsamo de Tolu. Por ela, justamente, começa sua descrição, dizendo serem:

"árvores mui grandes de que se fazem eixos para engenhos, cuja madeira é pardaça e incorruptível. Quando lavram esta madeira cheira a rua toda a bálsamo, e todas as vezes que se queira cheira muito bem. Desta árvore se tira o bálsamo suavíssimo [...] que é grosso e da cor do arrobe, o qual é milagroso para curar feridas frescas, $e$ para tirar os sinais delas no rosto." ${ }^{35}$

Ainda sobre esse tópico, mais uma árvore merece a atenção de Soares de Sousa:

"De tão santa árvore como a do bálsamo merece ser compa-
nheira e vizinha a que chamam copaíba, que é árvore grande
cuja madeira não é muito dura, e tem a cor pardaça; e faz-se
dela tabuado; a qual não dá fruto que se coma, mas um
óleo santíssimo em virtude, o qual é da cor e clareza
de azeite sem sal; e antes de se saber de sua virtude
servia de noite nas candeias. Para se tirar este óleo das
árvores lhes dão um talho com um machado acima do
pé, até que lhe chegam à veia, e como lhe chegam corre
este óleo em fio, e lança tanta quantidade cada árvore que
há algumas que dão duas botijas cheias, que tem cada uma
quatro canadas. Este óleo tem muito bom cheiro, e é
excelente para curarferidas frescas, e as que levam pontos
da primeira curam, soldam se as queimam com ele, e as
estocadas ou feridas que não levam pontos se curam com
ele, sem outras mezinhas; com o qual se cria a carne até
encourar, e não deixa criar nenhuma corrupção nem ma-
téria. Para frialdades, dores de barriga e pontadas de frio
é este óleo santíssimo, e é tão sutil que se vai de todas as
vasilhas, se não são vidradas; e algumas pessoas querem
afirmar que até no vidro mingua; e quem se untar com
este óleo há de se guardar do ar, porque é prejudicial." 36

A publicação de um texto informativo como esse de Soares de Sousa poderia ter contribuído para tornar conhecido dos médicos e farmacêuticos portugueses um tão precioso medicamento. No entanto, sua publicação - primeiramente parcial, depois integral - foi realizada apenas em finais do século XIX.

Um outro trabalho escrito em português merece menção aqui, por ter uma história singular. Ele foi elaborado pelo jesuíta Fernão Cardim durante sua estada no Brasil em finais do século XVI (provavelmente 
em 1584). ${ }^{37}$ Ao voltar a Portugal, o navio em que viajava caiu em mãos de piratas, que levaram o precioso manuscrito e o venderam. Isso é contado não por Cardim, mas por S. Purchas editor do texto em $1625 .{ }^{38}$ Séculos mais tarde, teve a verdadeira a autoria estabelecida, saindo à público, finalmente, em português. A citação a seguir, extraída da edição inglesa, fala, mais uma vez, da "cabueriba" (há uma pequena diferença na grafia) e da copaíba:

\section{"Das árvores que servem para medicamentos. Cabueriba. [...] \\ Um medicamento. Para ferimentos.}

Cabueriba é muito grande e estimado pelo bálsamo que tem; para obter este bálsamo eles furam o córtex da árvore, e colocam um pouco de lã de algodão nos cortes, e depois de alguns dias eles vão para colher o óleo que destilou. Os portugueses o chamam de Bálsamo, porque é muito parecido com as videira de Engedi, serve para ferimentos recentes, e tira todo o escarro: cheira muito bem e dele, e do córtex da árvore eles fazem contas e outras coisas aromáticas. As florestas onde crescem cheiram bem, e os animais vão e se esfregam contra esta árvore, pareciera que para se curarem de algumas molésticas. A madeira é dentre as melhores deste país, porque é muito forte e pesada, e algumas são tão grandes, que com elas fazem as vigas, eixos, parafusos e tornos para seus Morros-de-Açúcar, são muito raras e se encontram principalmente na Capitania do Espírito Santo. Cupayba. Para ferimentos.

Cupayba é uma figueira, comumente muito alta, reta e grande, contém muito óleo; para obté-lo, cortam a árvore no meio, onde tem a véia, e e lá tem este óleo em tanta abundância, que algumas produzem um quarto de óleo e mais, é muito claro, da cor de óleo, e é muito útil para ferimentos, e tira todo o escarro. Também serve para lâmpadas, e queima bem, os animais, conhecendo essa sua virtude, vem e se esfregam lá. Há grande reserva, a madeira não serve para nada." 39

Escolhemos como terceiro exemplo, um estudo elaborado em latim e publicado na Europa em sua época e que viria a ser traduzido e publicado em português muito mais tarde. Trata-se do texto que saiu sob o nome de Willem Piso, médico holandês que passou alguns anos no Brasil, durante a dominação holandesa no nordeste. A História Natural e Médica da Índia Ocidental saiu dos prelos pela primeira vez em latim em 1648 (a data da publicação em português é 1948), e contém o que se considera a primeira descrição mais detalhada de diversas plantas medicinais brasileiras.

A publicação dessa obra e a divulgação que teve na Europa teriam certamente facilitado a muitos o conhecimento da copaíba, da cabureiba (identificada por Piso como o bálsamo do Peru, com qualidades inferiores à copaíba) e de outras plantas medicinais brasileiras. Piso inicia o "artigo" sobre a copaíba observando que:

\begin{abstract}
"os americanos chamam todas as resinas odorosas e gomas pelo nome comum de Copal, e que distinguem por nomes peculiares as suas várias espécies. Assim, também os brasileiros denominaram esta árvore, indubitavelmente a principal das resiniferas, Copaliba ou Copaíba." 40
\end{abstract}

O texto continua com a descrição botânica da planta, a maneira de coletar seu óleo e suas virtudes medicinais observando:

"Não somente é eficaz pela admirável virtude de alimpar e consolidar, e para curar quaisquer feridas (mormente dos nervos), ainda no principio, e as mordeduras de serpentes, e eliminar as cicatrizes, mas por todos os habitantes e por mim foi observado que é de grande utilidade, ministrado internamente. Entretanto não é de tão suave odor, como quer Maffeu. É quente no segundo grau, grosso e muito pingue e resinoso. $[\ldots]$

É bom untar com ele o peito quando o estômago se acha debilitado, e o ventre, quando afligido por dores de cólicas frias. Algumas gotinhas dadas convenientemente por via oral aumentam as forças às vísceras e restituem-lhes o tono: também refreiam os fluxos das mulheres, as diarreias e as gonorréias. Contra estes mesmos males, com bom sucesso, é injetado no ânus por meio de clisteres, no pênis, por meio de uma seringa com água de tanchagem açucarada, ou dissolvido com óleo de rosas." ${ }^{41}$

Um último exemplo, entre os muitos que poderíamos apresentar, é o de João Ferreira da Rosa, médico formado pela Universidade de Coimbra autor do Tratado Único da Constituição Pestilencial de Pernambuco, publicado em 1694. Nesse livro, Rosa fala de uma doença desconhecida pelos europeus até sua chegada às Américas: a febre amarela. Para curar a doença, prescreve diversas plantas nativas utilizadas pelos indígenas em sua terapêutica, como a raiz de angélico e o maracujá-mirim. Já para prevenir o contágio da doença, Rosa recomenda lançar em fogueiras, junto com outros materiais, o óleo de copaíba. O médico declara, ainda, ter aprendido com os índios tapuias a usar o óleo de copaíba contra as disenterias. A lista dos males a serem curados com esse óleo é, segundo Rosa, bastante longa, sendo contraveneno nas pestes e antídoto nas mordeduras de serpentes. Agia ainda nas quebraduras, na supressão da urina, erisipelas, dores, paralisia e muitas outras doenças de causas frias, pois seguindo a medicina humoral, Rosa considerava o óleo de copaíba quente e seco. ${ }^{42}$

Os relatos de viagens e os estudos mandados realizar sobre as drogas americanas em muito devem ter facilitado sua introdução nos textos médicos. Assim, o bálsamo de copaíba, mas também o do Peru, o de Tolu e alguns outros bálsamos, têm presença frequente nas farmacopeias, de uso obrigatório em diferentes países da Europa já no século XVII.

No entanto, a política portuguesa de manter em segredo as informações sobre suas colônias, em especial sobre o Brasil, teria levado, também no caso do uso das drogas medicinais brasileiras, a uma história diferente quando comparada a outros países. Assim, os conhecimentos sobre as plantas medicinais nativas praticamente não foram incorporados às farmacopeias e matéria médica portuguesas ou brasileiras, a não ser tardiamente e por via indireta. Aliás, a própria história desse tipo de literatura em Portugal e no Brasil é bastante interessante.

A primeira farmacopeia portuguesa, a Pharmacopea Lusitana, uma obra de Caetano de Santo António, data de 1704 e teve 2 outras edições. Entretanto, nem essa nem outras publicadas nas décadas seguintes obtiveram o status de farmacopeias oficiais. Na verdade, apenas em 1772, e mais uma vez no âmbito da reforma da Universidade de Coimbra, é que se ordena à Congregação da Faculdade de Medicina a elaboração de uma farmacopeia oficial para o Reino Português (incluindo, portanto, o Brasil).$^{43}$ Por tal farmacopeia deveriam ser:

“instruídos, examinados, governados, e visitados [...] todos os boticários de qualquer estado, e condição que sejam. Ficando proibidas, depois da publicação dela, todas e quaisquer outras Farmacopeias compostas por Colégios, Faculdades, ou professores de medicina, e farmácia; ou sejam nacionais, ou sejam estrangeiros, para que nenhuma delas possa mais servir de regimento aos boticários; sendo todos obrigados a praticar segundo o método estabelecido na Farmacopeia do reino ordenada pela Congregação da Faculdade." 44 
Convém lembrar que, também, para outras disciplinas da Universidade de Coimbra, deveria ser elaborado um compêndio, sempre a cargo do professor responsável. Da mesma forma que várias décadas se interpõem entre a promulgação dos Estatutos e a composição dos textos de Física, Química e História Natural, a Farmacopéia Geral esperaria cerca de 20 antes para vir a público. Essa obra, elaborada pelo professor de Matéria Médica e Arte Farmacêutica da Faculdade de Medicina, o Dr. Francisco Tavares, foi publicada pela primeira vez em 1794, sem o nome do autor. ${ }^{45}$

Segundo J. Rui Pita, estudioso português de história da farmácia, a Farmacopéia Geral está fortemente baseada na Pharmacopoeia Edimburgensis e também na Pharmacopoeia Suecica ${ }^{46} \mathrm{O}$ texto de Tavares apresenta 168 símplices do reino vegetal, sendo 30 de origem africana e 24 de origem americana. Entre eles, os bálsamos já mencionados. Certamente, a incorporação das drogas americanas às farmacopeias portuguesas deveu-se mais ao que Pita denomina de "influência européia" (pois essas drogas haviam sido muito antes incorporadas às diferentes farmacopeias) do que ao conhecimento desses materiais a partir das descrições e trabalhos de estudiosos nativos. ${ }^{47}$

A Farmacopéia Geral, conhecida como a "do Dr. Tavares", teve outras edições, sem alterações, em 1823 e 1824, sendo substituída apenas em 1835 pelo texto elaborado por A. A. da Silveira Pinto. ${ }^{48}$ Nessa época, o Brasil já era um país independente e, numa primeira aproximação, poderíamos pensar que, liberto das amarras do governo português, o Brasil seguiria um rumo próprio, pois, Portugal havia proibido, até à chegada da Família Real ao Brasil, em 1808, o estabelecimento de cursos superiores, a instalação de prelos e mantinha o controle absoluto da entrada de livros. Isso teria impedido a aplicação de medidas convenientes aos interesses da colônia no que se relaciona, por exemplo, ao estudo e prescrição mais acentuados de plantas medicinais nativas.

Entretanto, verificamos que até 1837, a obra do Dr. Tavares foi a farmacopeia oficial no Brasil. Nessa data, ela ganhou a "companhia" do francês Codex Medicamentarius. Anos mais tarde, uma nova legislação se referia a uma Farmacopéia Brasiliense, que:

“[...] depois de publicada [...] os Boticários deverão ter os remédios preparados segundo as fórmulas dessa farmacopéia, o que não inibe que os possam ter segundo as fórmulas de outras farmacopéias para satisfazerem às prescrições dos facultativos". ${ }^{49}$

Era o ano de 1851 e, como a Farmacopéia Brasiliense continuava apenas um projeto, a farmacopeia francesa reinava absoluta como oficial no Brasil. Os boticários, no entanto, deveriam ter em seus estabelecimentos, outros livros e farmacopeias, como a portuguesa de Silveira Pinto. Em 1882 (ainda sem uma farmacopeia brasileira), a lista de livros foi ampliada, mas o Codex francês seguia como principal e obrigatório. ${ }^{50}$

Finalmente, em 1917, ao menos um estado brasileiro ganhou uma farmacopeia obrigatória, elaborada por estudiosos nativos. Nessa obra, a Pharmacopea Paulista, que pretendia encerrar "em si a genese da Pharmacopéa Nacional, como mais cedo ou mais tarde ha de se verificar", encontramos as descrições e indicações de como preparar os bálsamos do Peru, de Tolu e de Copaíba. ${ }^{51}$

Algum tempo mais tarde, em 1926, o Brasil acabou ganhando, por decreto, sua farmacopeia, mas teria que esperar ainda 3 anos para vê-la publicada. Novamente, os 3 mencionados bálsamos têm lugar, agora, em artigos mais longos do que os constantes na Pharmacopea Paulista e com indicação dos tipos de formulação de que participavam. ${ }^{52}$

A segunda edição da Farmacopéia dos Estados Unidos do Brasil, em 1959, excluiria uma longa lista de símplices, sendo que uma parte deles passaria a figurar apenas no Formulário Nacional, então em fase de preparação. O bálsamo de copaíba foi um dos excluídos da Farmacopéia e não teve lugar no Formulário Nacional. ${ }^{53}$

Hoje, esse bálsamo é ainda amplamente utilizado na preparação de cosméticos e na medicina popular, da mesma forma que fora nos séculos anteriores em terras brasileiras. Pois, como notaram pricipalmente os naturalistas estrangeiros em suas viagens pelo interior do Brasil no século XIX, os habitantes das terras distantes dos grandes centros se valiam de grande quantidade de plantas medicinais totalmente desconhecidas dos médicos e boticários. ${ }^{54}$

A grande flora brasileira apenas recentemente tem recebido a atenção de estudiosos que buscam recuperar um conhecimento nativo que serviu, e ainda serve, para a cura de inúmeras doenças. Procura-se realizar o que, de certa forma, está há 5 séculos esperando para ver a luz.

\section{AGRADECIMENTOS}

FAPESP, CNPq, University College London.

\section{REFERÊNCIAS}

1. Bellamy, D.; Pfister, A.; World Medicine, Blackwell: Oxford/Cambridge, 1992, p. 24-26; Singer, I.; Alder, C., eds.; The Jewish Encyclopedia, Funk and Wagnalls: New York, 1901-1906, I: 476-7.

2. Plinio; Natural History, Harvard University Press: Cambridge, 1986, livro 12, p. 53; Whiston, W., ed.; The Works of Flavius Jospehus, Hendrickson: Peabody, 1992, “Ant.” VIII. 6, § 6; xv. 4, § 2; “B. J.” I. 6, § 6; $18, \S 5$; IV. $8, \S 3$.

3. Dioscorides; The Greek Herbal of Dioscorides, Hafner: New York, 1959, vol. 1, p. 18; Laguna, A.; Pedacio Dioscorides Anazarbeo, A Cerca de la Matéria Medicinal; V. Cabrera: Valencia, cap. 18.

4. Renaud, H. P. J.; Colin, G. S., eds. ; Tuhfat Al-Ahbab-Glossaire de la Matière Médicale Marocaine, Librarie Orientaliste Paul Geuthner: Paris, 1934, ent. 61, 257 e 265.

5. Grieve, M.; A Modern Herbal, J. Cape: London, 1931, I: 78-9.

6. Gesner, C.; The Treasure of Euonymus, Iohn Daie: London, 1559, p. 247-98.

7. Ibid., 262.

8. Ibid., 261.

9. West, D.; The William and Mary Quarterly 1993, 49, 274; Akin, J.; Morgan, T.; Johnston, W.; General Biography or Lives..., T. Davison: London, 1807, VI: 604.

10. Angleria, P. M.; The Decades of the Newe worlde or West India Conteynyng the Nauigations and Conquestes of the Spanyardes, Guilhelmi Powel: London, 1555, 134r.

11. Idem; De Nouo Orbe, or The Historie of the West Indies, Thomas Adams: London, 1612, 268v.

12. Fernandez de Oviedo; Historia General y Natural de las Índias, Iuam Cromberger: Sevilla, 1535.

13. Laguna, A.; op. cit.

14. Monardes, N.; Herbolaria de Índias, D. F. Turner: México, 1990, p. 29-30.

15. López Piñero, J. M.; Fresquet Freber, J. L.; López Terrada, M. L.; Pardo Tomás. J.; Medicinas, Drogas y Alimentos Vegetales del Nuevo Mundo, Min. Sal. y Cons.: Madrid, 1992, p. 217 et seq.

16. Soares de Sousa, G.; Tratado Descritivo do Brasil in 1587, Ed. Nacional: São Paulo, 1987; Cardim, F.; Tratado da Terra e da Gente do Brasil, Ed. J. Leite: Rio de Janeiro, 1925.

17. Serafim Leite; Artes e Ofícios dos Jesuítas no Brasil (1549-1760), Brotéria/Livros de Portugal: Lisboa, 1953, p. 86.

18. Anchieta, J.; Cartas Inéditas, Ed. da Fundação Getúlio Vargas: São Paulo, 1989, p. 43.

19. Leite; op. cit., 86; Fleck, E. C. D.; Rev. Hist. Univ. Complutense 2006, $32,153$. 
20. Arata, P.; La Biblioteca 1898, 2:7, 419-46; 2:8, 185-92; http://www.bvp. org.py/biblio_htm/montenegro/monteneg.htm, acessada em Outubro 2009.

21. Biblioteca Nacional do Rio de Janeiro, MSS I-15-02-02.

22. Leite, S., ed.; Cartas dos Primeiros Jesuítas no Brasil, Comissão do IV Centenário: São Paulo, 1954, I:. 337; II: 362-3.

23. Ibid., $11 \mathrm{v}$.

24. Ibid., 37-9.

25. Ibid., 55-7.

26. Ibid., 10.

27. Ibid., 11.

28. Veiga Jr, V. F.; Pinto, A. C.; Quim. Nova 2002, 25, 273.

29. Wehling, A.; Wehling, M. J. C.; Formação do Brasil Colonial, Nova Fronteira: Rio de Janeiro, 1994, p. 196 et seq.

30. Purchas, S.; Purchas, His Pilgrimes In Fiue Bookes; Henry Fetherstone: London, 1625, 1289, aqui o editor fala sobre o roubo de um manuscrito.

31. Antonil, A. J.; Cultura e Opulência do Brasil, Itatiaia/Edusp: Belo Horizonte/São Paulo, 1982.

32. Ferraz, M. H. M.; As Ciências em Portugal e no Brasil (1772-1822): O Texto Conflituoso da Química, FAPESP/EDUC: São Paulo, 1997, p. 31 et seq.

33. Academia das Ciências de Lisboa, "Historia do Descobrimento da Cochonilha no Brasil... Escripta por José Henriques Ferreira”, Ms Azul, 374, "Memorias Fisicas, e Economicas que não tiveram lugar nas colleçoens da Academia", ff. 342v.

34. Ibid.

35. Soares de Sousa, G.; Tratado descritivo do Brasil em 1587, Nacional: São Paulo, 1987, p. 202.

36. Ibid., 202-3

37. Massimi, M.; Memorandum 2003, 5, 69.
38. Purchas, op. cit., 1289.

39. Ibid., 1308 .

40. Piso, W.; História Natural e Médica da Índia Ocidental, Ministério da Educação e Cultura/Instituto Nacional do Livro: Rio de Janeiro, 1957, p. 270-2.

41. Ibid.

42. Ferreira da Rosa, J.; Tratado Único da Constituição Pestilencial de Pernambuco, Arquivo Público Estadual: Recife, 1956, p. 281.

43. Pita, R. J.; Farmácia, Medicina e Saúde Pública em Portugal (17721836), Minerva: Coimbra, 1996, p. 171-2; 201- 6.

44. Estatutos da Universidade de Coimbra; Regia Of. Typografica: Lisboa, 1772, III: 133.

45. Sousa Dias, J. P.; Medicamento, História e Sociedade 1995, 6, 1.

46. Pita, op. cit., 204, 224-5.

47. Ibid., 222.

48. Ibid., 239.

49. Farmacopéia dos Estados Unidos do Brasil, $2^{\mathrm{a}}$ ed., Ind. Graf. Siqueira: São Paulo, 1959, xxiv et seq.

50. Ibid.

51. Pharmacopea Paulista, Casa Espindola: São Paulo, 1917, 43-4; 92-3, respectivamente.

52. Pharmacopeia dos Estados Unidos do Brasil, Nacional: São Paulo, 1929, p. 110-1; 113-4.

53. Farmacopéia dos Estados Unidos do Brasil, $2^{\mathrm{a}}$ ed., op. cit., xxxi.

54. Alfonso-Goldfarb, A. M.; Ferraz. M. H. M. Em 1898: Sanidad y Ciencia em España y Latinoamérica durante el Cambio de Siglo; Puerto Sarmiento, F. J.; Alegre Perez, M. E.; Rey Bueno, M. M., eds.; Doce Calles: Madrid, 1999, p. 40-43. 